Article

\title{
A New Analytical Approach for Nonlinear Global Buckling of Spiral Corrugated FG-CNTRC Cylindrical Shells Subjected to Radial Loads
}

\author{
Tho Hung Vu ${ }^{1}$, Hoai Nam Vu ${ }^{1}$, Thuy Dong Dang ${ }^{1}$, Ngoc Ly Le ${ }^{2}$, Thi Thanh Xuan Nguyen ${ }^{1}$, \\ Nguyen-Thoi Trung $3,4(\mathbb{D}$ and Thi Phuong Nguyen $3,4, * \mathbb{C}$ \\ 1 Faculty of Civil Engineering, University of Transport Technology, Hanoi 100000, Vietnam; \\ hungvt@utt.edu.vn (T.H.V.); hoainam.vu@utt.edu.vn (H.N.V.); dongdt@utt.edu.vn (T.D.D.); \\ xuanntt@utt.edu.vn (T.T.X.N.) \\ 2 Faculty of Fundamental Science for Engineering, University of Transport Technology, Hanoi 100000, \\ Vietnam; lyln@utt.edu.vn \\ 3 Division of Computational Mathematics and Engineering, Institute for Computational Science, \\ Ton Duc Thang University, Ho Chi Minh City 700000, Vietnam; nguyenthoitrung@tdtu.edu.vn \\ 4 Faculty of Civil Engineering, Ton Duc Thang University, Ho Chi Minh City 700000, Vietnam \\ * Correspondence: nguyenthiphuong@tdtu.edu.vn
}

Received: 1 March 2020; Accepted: 7 April 2020; Published: 9 April 2020

\begin{abstract}
The present paper deals with a new analytical approach of nonlinear global buckling of spiral corrugated functionally graded carbon nanotube reinforced composite (FG-CNTRC) cylindrical shells subjected to radial loads. The equilibrium equation system is formulated by using the Donnell shell theory with the von Karman's nonlinearity and an improved homogenization model for spiral corrugated structure. The obtained governing equations can be used to research the nonlinear postbuckling of mentioned above structures. By using the Galerkin method and a three term solution of deflection, an approximated analytical solution for the nonlinear stability problem of cylindrical shells is performed. The linear critical buckling loads and postbuckling strength of shells under radial loads are numerically investigated. Effectiveness of spiral corrugation in enhancing the global stability of spiral corrugated FG-CNTRC cylindrical shells is investigated.
\end{abstract}

Keywords: FG-CNTRC; spiral corrugated cylindrical shells; postbuckling behavior; radial load; analytical approach

\section{Introduction}

Due to many excellent mechanic properties, functionally graded material (FGM) has been popularly applied in engineering designs, such as military systems, nuclear reactors, civil engineering and other technologies. Static and dynamic behavior of FGM cylindrical shells is the problem which is especially a focus by many authors.

Shen [1,2] studied the postbuckling behavior of FGM cylindrical shells in a thermal environment subjected to axial compressive and radial loads. The stability equation system was established by using the Donnell shell theory and the von Kármán nonlinearities combined with the prebuckling deformations and the geometrical imperfection. Nonlinear buckling behavior of higher-order shear deformable piezolaminated cylindrical shells subjected to radial pressure loads taking into account the temperature dependent effects of materials and geometrical imperfection was presented by Shen and Xiang [3]. By using the energy method, Huang and Han [4,5] studied the linear and nonlinear buckling behavior of imperfect and perfect FGM cylindrical shells subjected to axial compressive loads. Sofiyev and Schnak [6] and Sofiyev [7-10] investigated the linear and nonlinear buckling and 
vibration behavior of FGM cylindrical shells and FGM truncated conical shells subjected to static and dynamic loads with different boundary conditions. By using the Lord-Shulman and Maxwell formulations, Heydarpour et al. [11] presented a thermoelastic approach to investigate the wave propagation of piezoelectric FGM cylindrical panels subjected to the thermal shock loads. Bagherizadeh et al. [12] investigated the nonlinear buckling of higher-order shear deformable FGM cylindrical shells surrounded by two-parameter Pasternak's elastic foundation subjected to combined axial and radial compressive loads. Allahkarami et al. [13] studied the dynamic buckling behavior of higher-order shear deformable FGM porous cylindrical shells with even and uneven porosity distribution types. Hakula and Laaksonen [14] discussed the frequency responses of perforated shells with uncertain materials and damage by using the higher-order finite element method.

Nonlinear buckling behavior of large deflection FGM and porous-core FGM spiral stiffened cylindrical shells subjected to axial compressive, radial and torsional loads with and without elastic foundation by using the improved Lekhnitskii's smeared stiffener technique and the Galerkin method was studied by Nam et al. [15-19]. Based on genetic algorithms and neural networks, Miller and Ziemiański [20] maximized the eigenfrequency gaps of laminated composite cylindrical shells.

Carbon nanotube-reinforced composite (CNTRC) is an advanced material which has gained particular interest in recent years. The postbuckling behavior of CNTRC cylindrical shells subjected to radial pressure, axial compression and torsion with temperature effects was investigated by Shen [21-23]. Two types of CNTRC, namely, uniformly distributed CNTRC (UD-CNTRC) and functionally graded CNTRC (FG-CNTRC) were discussed. By employing the boundary layer theory and the singular perturbation technique, Shen and Xiang [24] investigated the postbuckling behavior of FG-CNTRC cylindrical shells with and without elastic foundation subjected to the combined axial compressive and radial loads in a thermal environment. Linear buckling behavior of first order shear deformable FG-CNTRC truncated conical shells subjected to radial loads was estimated by Jam and Kiani [25] based on the linear membrane analysis and the adjacent equilibrium criterion. Kiani et al. [26-28] studied the linear free vibration and dynamic responses of FG-CNTRC conical shells, cylindrical panels and skews cylindrical shells. Hajmohammad et al. [29] investigated the thermal and moisture effect on the dynamic responses of a submerged viscoelastic agglomerated carbon nanotube (CNT) cylindrical shell subjected to earthquake loads. Smart control and vibration behavior of viscoelastic laminated sandwich conical shells subjected to hygrothermal loads by using the layerwise theory was proposed by Hajmohammad et al. [30]. The shells are made of outer piezoelectric layers with carbon fibers or carbon nanotubes (CNTs) core layers. Hosseini and Kolahchi [31] presented the viscoelastic dynamic responses of higher order shear deformable FG-CNTRC cylindrical shells subjected to seismic impact in a hygrothermal environment with the Kelvin-Voigt structural damping and the second kind Hankel function of fluid-shell interaction. By using the Galerkin method, fourth-order Runge-Kutta method and Budiansky-Roth dynamic buckling criterion, the nonlinear dynamic buckling analysis of first-order shear deformable FG-CNTRC cylindrical shells subjected to axial power-law time-varying displacement loads was investigated by Jiao et al. [32]. A general approach of free and linear vibration analysis of rotating shear deformable FG-CNTRC cylindrical shells with arbitrary boundary conditions was proposed by Qin et al. [33]. By using the variational differential quadrature method, Torabi et al. [34] proposed a unified numerical method on the thermal buckling analysis of higher-order shear deformable FG-CNTRC plates with different shapes, taking into account the temperature-dependent material properties. The magneto-electro-elastic free vibration behavior of a numerical approach of higher-order deformable FG-CNTRC rectangular and skew plates by using the equations of motion and Hamilton's principle was developed by Vinyas [35]. SafarPour et al. [36] studied the linear buckling and free vibration analysis of a high speed rotating piezoelectric FG-CNTRC cylindrical shell by developing the Hamilton's principle, Navier and generalized differential quadrature methods. By using the first order shear deformation theory (FSDT), Zhao et al. [37] and Sofiyev et al. [38] investigated the free vibration and buckling behavior of FG-CNTRC truncated conical panels and shells. Ghasemi et al. [39] studied the vibration behavior of SWCNTs/fiber/polymer/metal laminated cylindrical shells with the 
agglomeration effects of continuously graded single walled carbon nanotubes (SWCNTs) based on the Kirchhoff Love's first approximation shell theory. Based on the FSDT, Arefi et al. [40] presented the elastic behavior of clamped-clamped and short-circuited cylindrical shells with piezoelectric face-sheets and a FG-CNTRC core layer subjected to thermal, electrical, and mechanical loads. Mallek et al. [41] investigated the geometrically nonlinear effects of FG-CNTRC classical thin shell panels with surface-bonded active piezoelectric layers while the electric potential linearly varies through the thickness. Chakraborty et al. [42] studied the nonlinear stability and vibration behavior of higher-order shear deformable FG-CNTRC laminated cylindrical shell panels by employing the Galerkin method and the neglect of inertia terms. By combining the sine and exponential power with cosine function, a new higher order shear deformation theory was developed and the linear vibration behavior of FG-CNTRC doubly-curved nanoshells was presented by Dindarloo and Li [43]. Khosravi et al. [44] studied the nonlinear buckling of FG-CNTRC beams subjected to uniform temperature rise and angular rotating employing the Timoshenko beam theory and the von Kármán nonlinearities. Three-dimensional nonlinear bending behavior of FG-CNTRC plates using the element-free Galerkin method based on the strain-rotation decomposition theorem was investigated by Zhou and Song [45]. Beni [46] studied the linear free vibration analysis of asymmetric sector FG-CNTRC face-sheet sandwich plates with different boundary conditions by using Carrera's unified formulation.

Due to the outstanding bearing capacity, the spiral corrugated cylindrical shells are very popular structures in engineering design [47]. In addition, this structure type is suitable with the actual manufacture technologies. This paper presents a new analytical approach of nonlinear buckling and postbuckling behavior of spiral corrugated FG-CNTRC circular cylindrical shells by applying an equivalent model. Spiral corrugation is homogenized by combining a homogenization technique with the coordinate transformation technique. By applying the Donnell shell theory with the nonlinear terms of strain-displacement relation, the three-state solution form of deflection and the Galerkin procedure, the nonlinear equilibrium equations are established. The effects of geometrical properties of corrugation and volume-fractions of CNT on the linear and nonlinear buckling behavior of shells is validated by numerical investigations.

\section{Equivalent Model of Spiral Corrugated FG-CNTRC Cylindrical Shells}

Consider a spiral corrugated nanocomposite FG-CNTRC cylindrical shell of longitudinal length $L$, thickness $h$, circumferential radius $R$, reinforced by aligned SWCNTs. In accordance with the manufacture technology, the spiral corrugated cylindrical shell is made by coiling a corrugated loop coil. Corrugation is considered in two cases of round and trapezoidal corrugations as shown in Figure 1a. The CNT is along the corrugated loop coil direction and the corrugated loop coil is defined in the local coordinate system $n, s, z$.

By using the geometrical relation, the number of corrugation waves of a loop coil $\mathrm{N}$ is related with corrugation angle by the expression

$$
\theta=\arcsin \left(\frac{N c}{\pi R}\right)
$$

where $N$ is the wave number of corrugation of a loop coil, and $c$ is the length of the half wave of corrugation (Figure 1b).

The geometrical parameters of corrugations are assumed to be small in comparison with those of the cylindrical shell. Therefore, a homogeneous technique for corrugated structure may be applied for modeling the global buckling behavior of shells. 

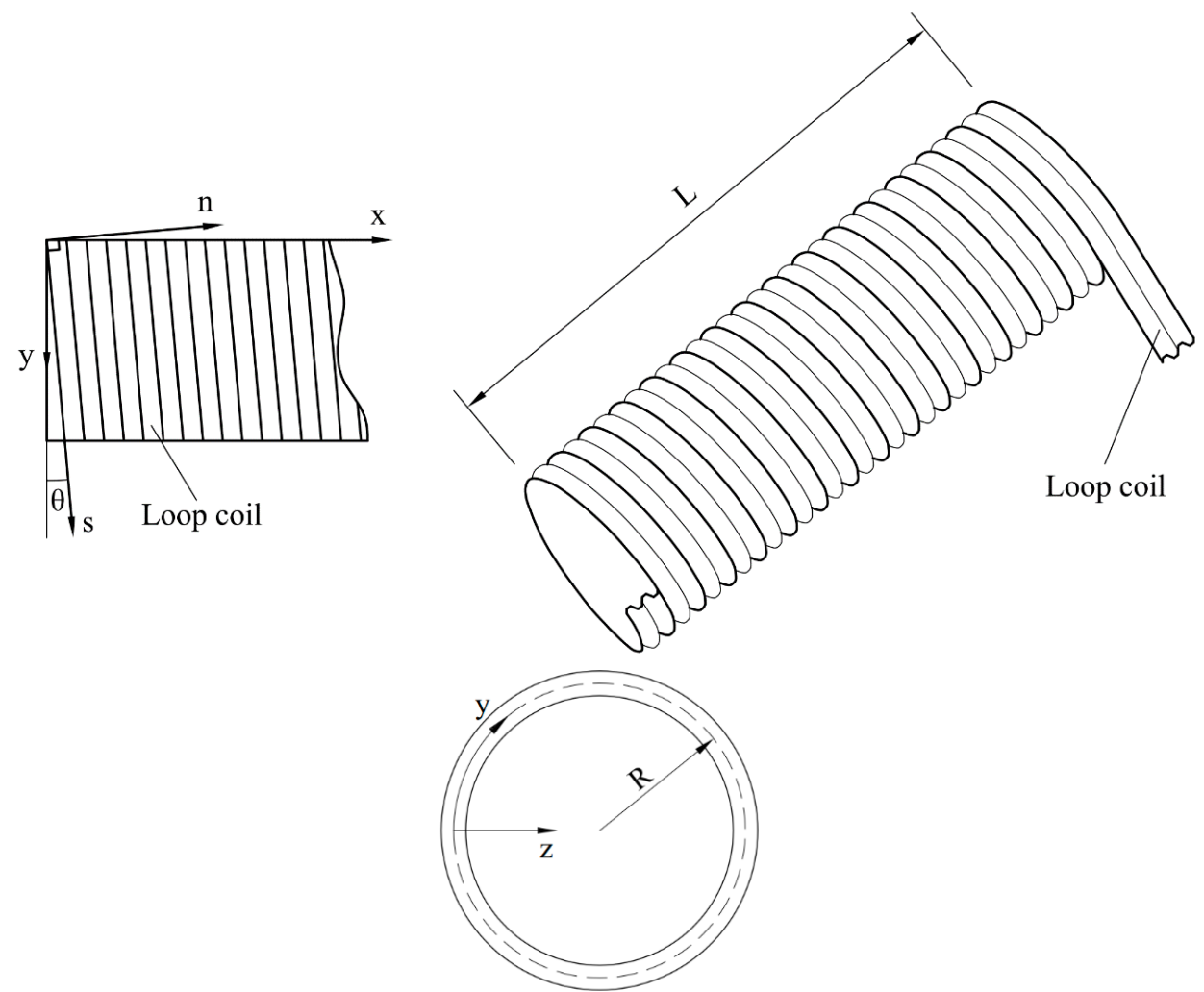

(a) Configuration and coordinate systems of shell
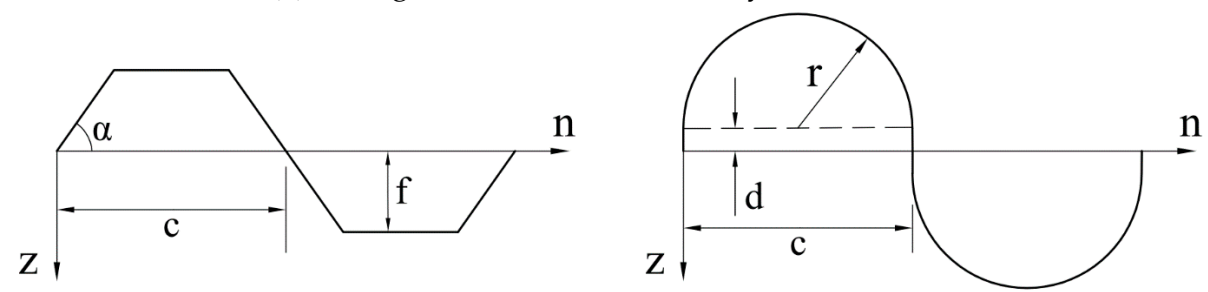

(b) Geometrical properties of corrugations

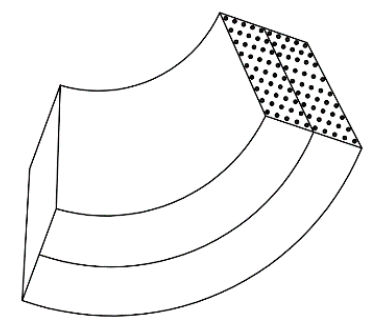

UD

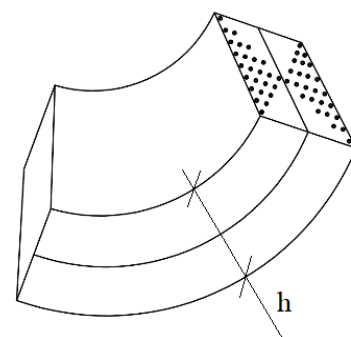

FG-X

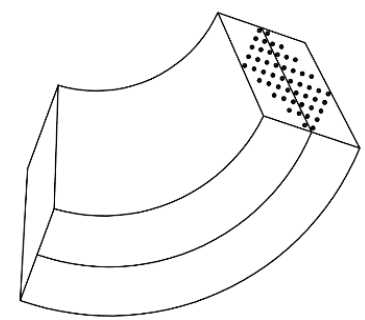

FG-O

(c) CNT distribution types

Figure 1. Geometrical properties and coordinate system of spiral corrugated functionally graded carbon nanotube reinforced composite (FG-CNTRC) cylindrical shells.

The spiral corrugated cylindrical shell is defined in a global coordinate system $x, y, z$. The origin is located at an end of the shell and on the middle surface of corrugations. The axes $x$ and $y=R \theta$ are in-plane coordinates in axial and circumferential directions of the shell, respectively, and the axis $z$ is in the direction of inward normal to the mid-surface, as shown in Figure 1a. The SWCNTs are reinforced into an isotropic polymer matrix through uniform distribution (UD) or functionally graded (FG) distribution in which the volume fraction of CNT continuously varies in the thickness direction of corrugation skin with two different types referred to as FG-O and FG-X (Figure 1c). The mid-surface of 
corrugation skin is CNT-rich for FG-O type and the internal surface of corrugation skin is enriched by CNTs in case of FG-X type. The CNT is along the spiral direction of corrugation. For the case of ring corrugated cylindrical shells, CNT is in the circumferential direction of shells ( $y$ direction).

The effective Young's moduli and shear modulus of the non-corrugated CNTRC shell panels are determined according to the extended rule of mixture as [21]

$$
\frac{\eta_{2}}{E_{11}}=\frac{V_{C N T}}{E_{11}^{C N T}}+\frac{V_{m}}{E^{m}}, E_{22}=\eta_{1} V_{C N T} E_{22}^{C N T}+V_{m} E^{m}, \frac{\eta_{3}}{G_{12}}=\frac{V_{C N T}}{G_{12}^{C N T}}+\frac{V_{m}}{G^{m}}
$$

where $E_{11}^{C N T}, E_{22}^{C N T}$ and $G_{12}^{C N T}$ are the Young's moduli and shear modulus of the carbon nanotube, respectively, $E^{m}$ and $G^{m}$ are the Young's modulus and shear modulus of the isotropic matrix, respectively.

Note that: Equation (2) is applied for non-corrugated CNTRC shell panels.

The coefficients $\eta_{j}(j=1,2,3)$, are known as the CNT efficiency parameters. $V_{C N T}$ and $V_{m}$ are the volume fractions of CNTs and matrix, respectively, and they are related to

$$
V_{C N T}+V_{m}=1
$$

The variation functions of the CNT volume fraction $V_{C N T}$ through the thickness of shell for three types of CNT distributions are considered as [26]

$$
V_{C N T}= \begin{cases}V_{C N T^{\prime}}^{*} & (U D), \\ 2\left(1-\frac{2|z|}{h}\right) V_{C N T^{\prime}}^{*} & (F G-O), \\ 2\left(\frac{2|z|}{h}\right) V_{C N T^{\prime}}^{*} & (F G-X),\end{cases}
$$

where $V_{C N T}^{*}$ is the total volume fraction of CNT.

The Poisson's ratio depends on the thickness and can be determined by [26]

$$
v_{12}=V_{C N T}^{*} v_{12}^{C N T}+V_{m} v^{m}
$$

where $v_{12}^{C N T}$ and $v^{m}$ are Poisson's ratios of CNT and the isotropic matrix, respectively.

Stress-strain relations for a non-corrugated CNTRC shell are expressed as (in the local coordinate system)

$$
\left(\begin{array}{l}
\sigma_{n} \\
\sigma_{s} \\
\sigma_{n s}
\end{array}\right)=\left(\begin{array}{ccc}
Q_{11} & Q_{12} & 0 \\
Q_{12} & Q_{22} & 0 \\
0 & 0 & Q_{66}
\end{array}\right)\left\{\begin{array}{l}
\varepsilon_{n} \\
\varepsilon_{s} \\
\gamma_{n s}
\end{array}\right\},
$$

where

$$
Q_{11}=\frac{E_{11}}{1-v_{12} v_{21}}, Q_{22}=\frac{E_{22}}{1-v_{12} v_{21}}, Q_{12}=\frac{v_{21} E_{11}}{1-v_{12} v_{21}}, Q_{66}=G_{12}
$$

In the local coordinate system, the internal force expressions of a CNTRC shell are presented by using the homogenization technique for corrugated panels reported by Xia et al.'s model [48] with the kinematic assumptions of the Kirchhoff theory, leading to

$$
\left\{\begin{array}{l}
N_{n} \\
N_{s} \\
N_{n s} \\
M_{n} \\
M_{s} \\
M_{n s}
\end{array}\right\}=\left\{\begin{array}{cccccc}
\bar{A}_{11} & \bar{A}_{12} & 0 & 0 & 0 & 0 \\
\bar{A}_{12} & \bar{A}_{22} & 0 & 0 & 0 & 0 \\
0 & 0 & \bar{A}_{66} & 0 & 0 & 0 \\
0 & 0 & 0 & \bar{D}_{11} & \bar{D}_{12} & 0 \\
0 & 0 & 0 & \bar{D}_{12} & \bar{D}_{22} & 0 \\
0 & 0 & 0 & 0 & 0 & \bar{D}_{66}
\end{array}\right\}\left\{\begin{array}{l}
\varepsilon_{n}^{0} \\
\varepsilon_{s}^{0} \\
\gamma_{n s}^{0} \\
\chi_{n} \\
\chi_{s} \\
2 \chi_{n s}
\end{array}\right\},
$$


where the stiffness matrix constituents of ring corrugated shells are determined as

$$
\begin{gathered}
\bar{A}_{11}=\frac{2 c}{\frac{I_{1}}{\hat{A}_{11}}+\frac{I_{2}}{\hat{D}_{11}}}, \bar{A}_{12}=\frac{\hat{A}_{12}}{\hat{A}_{11}} \bar{A}_{11} \quad \bar{A}_{22}=\frac{\bar{A}_{12} \hat{A}_{12}}{\hat{A}_{11}}+\frac{l}{c} \frac{\hat{A}_{11} \hat{A}_{22}-\hat{A}_{12}^{2}}{\hat{A}_{11}} \bar{A}_{66}=\frac{c}{l} \hat{A}_{66} \\
\bar{D}_{11}=\frac{c}{l} \hat{D}_{11}, \quad \bar{D}_{12}=\frac{\hat{D}_{12}}{\hat{D}_{11}} D_{11} \quad \bar{D}_{22}=\frac{1}{2 c}\left(I_{2} \hat{A}_{22}+I_{1} \hat{D}_{22}\right) \quad \bar{D}_{66}=\frac{l}{c} \hat{D}_{66}
\end{gathered}
$$

with $l=\frac{2 f}{\sin \alpha}+c-\frac{2 f}{\tan \alpha}, I_{1}=\frac{4 f \cos \alpha}{3 \sin \alpha}+2 c-\frac{4 f}{\tan \alpha}, I_{2}=\frac{4 f^{3}}{3 \sin \alpha}+2 f^{2}\left(c-\frac{2 f}{\tan \alpha}\right)$, for trapezoidal corrugation and $l=\pi r+2 d, c=2 r, I_{1}=\pi r, I_{2}=\frac{4 d^{3}}{3}+2 \pi d^{2} r+8 d r^{2}+\pi r^{3}$, for round corrugation; and the stiffness matrix constituents of pre-corrugated shell panels are calculated by

$$
\hat{A}_{i j}=\int_{-\frac{h}{2}}^{\frac{h}{2}} Q_{i j} d z, \quad \hat{D}_{i j}=\int_{-\frac{h}{2}}^{\frac{h}{2}} Q_{i j} z^{2} d z .
$$

By using the coordinate transformation procedure, the internal force terms of a CNTRC cylindrical shell in global coordinate system $(O x y)$ are expressed by

$$
\left\{\begin{array}{c}
N_{x} \\
N_{y} \\
N_{x y} \\
M_{x} \\
M_{y} \\
M_{x y}
\end{array}\right\}=\left\{\begin{array}{cccccc}
A_{11} & A_{12} & A_{16} & 0 & 0 & 0 \\
A_{21} & A_{22} & A_{26} & 0 & 0 & 0 \\
A_{61} & A_{62} & A_{66} & 0 & 0 & 0 \\
0 & 0 & 0 & D_{11} & D_{12} & D_{16} \\
0 & 0 & 0 & D_{21} & D_{22} & D_{26} \\
0 & 0 & 0 & D_{61} & D_{62} & D_{66}
\end{array}\right\}\left\{\begin{array}{c}
\varepsilon_{x}^{0} \\
\varepsilon_{y}^{0} \\
\gamma_{x y}^{0} \\
-w_{, x x} \\
-w_{, y y} \\
-2 w_{, x y}
\end{array}\right\},
$$

where

$$
\begin{aligned}
& A_{11}=\bar{A}_{11} \cos ^{4} \theta+2\left(\bar{A}_{12}+2 \bar{A}_{66}\right) \sin ^{2} \theta \cos ^{2} \theta+\bar{A}_{22} \sin ^{4} \theta \\
& A_{12}=\left(\bar{A}_{11}+\bar{A}_{22}-4 \bar{A}_{66}\right) \sin ^{2} \theta \cos ^{2} \theta+\bar{A}_{12}\left(\sin ^{4} \theta+\cos ^{4} \theta\right), \\
& A_{16}=\left(\bar{A}_{11}-\bar{A}_{22}-2 \bar{A}_{66}\right) \sin \theta \cos ^{3} \theta+\left(\bar{A}_{11}-\bar{A}_{22}+2 \bar{A}_{66}\right) \sin ^{3} \theta \cos \theta, \\
& A_{22}=\bar{A}_{11} \sin ^{4} \theta+2\left(\bar{A}_{12}+2 \bar{A}_{66}\right) \sin ^{2} \theta \cos ^{2} \theta+\bar{A}_{22} \cos ^{4} \theta \\
& A_{26}=\left(\bar{A}_{11}-\bar{A}_{22}-2 \bar{A}_{66}\right) \sin ^{3} \theta \cos \theta+\left(\bar{A}_{11}-\bar{A}_{22}+2 \bar{A}_{66}\right) \sin \theta \cos ^{3} \theta, \\
& A_{66}=\left(\bar{A}_{11}+\bar{A}_{22}-2 \bar{A}_{12}-2 \bar{A}_{66}\right) \sin ^{2} \theta \cos ^{2} \theta+\bar{A}_{66}\left(\sin ^{4} \theta+\cos ^{4} \theta\right), \\
& D_{11}=\bar{D}_{11} \cos ^{4} \theta+2\left(\bar{D}_{12}+2 \bar{D}_{66}\right) \sin ^{2} \theta \cos ^{2} \theta+\bar{D}_{22} \sin ^{4} \theta \\
& D_{12}=\left(\bar{D}_{11}+\bar{D}_{22}-4 \bar{D}_{66}\right) \sin ^{2} \theta \cos ^{2} \theta+\bar{D}_{12}\left(\sin ^{4} \theta+\cos ^{4} \theta\right), \\
& D_{16}=\left(\bar{D}_{11}-\bar{D}_{22}-2 \bar{D}_{66}\right) \sin \theta \cos ^{3} \theta+\left(\bar{D}_{11}-\bar{D}_{22}+2 \bar{D}_{66}\right) \sin ^{3} \theta \cos \theta, \\
& D_{22}=\bar{D}_{11} \sin ^{4} \theta+2\left(\bar{D}_{12}+2 \bar{D}_{66}\right) \sin ^{2} \theta \cos ^{2} \theta+\bar{D}_{22} \cos ^{4} \theta \\
& D_{26}=\left(\bar{D}_{11}-\bar{D}_{22}-2 \bar{D}_{66}\right) \sin \sin ^{3} \theta \cos \theta+\left(\bar{D}_{11}-\bar{D}_{22}+2 \bar{D}_{66}\right) \sin \theta \cos ^{3} \theta, \\
& D_{66}=\left(\bar{D}_{11}+\bar{D}_{22}-2 \bar{D}_{12}-2 \bar{D}_{66}\right) \sin ^{2} \theta \cos ^{2} \theta+\bar{D}_{66}\left(\sin ^{4} \theta+\cos ^{4} \theta\right) .
\end{aligned}
$$

Clearly, the spiral corrugated FG-CNTRC cylindrical shells are equivalent to the non-corrugated FG-CNTRC cylindrical shells characterized by stiffness matrix terms $A_{i j}, D_{i j}$ in Equation (9). 


\section{Governing Equations}

According to the von Karman nonlinear strain-displacement relations, the strain components at the middle surface of equivalent circular cylindrical shells are of the form [49]

$$
\begin{aligned}
& \varepsilon_{x}^{0}=\frac{\partial u}{\partial x}+\frac{1}{2}\left(\frac{\partial w}{\partial x}\right)^{2}, \\
& \varepsilon_{y}^{0}=\frac{\partial v}{\partial y}-\frac{w}{R}+\frac{1}{2}\left(\frac{\partial w}{\partial y}\right)^{2}, \\
& \gamma_{x y}^{0}=\frac{\partial u}{\partial y}+\frac{\partial v}{\partial x}+\frac{\partial w}{\partial x} \frac{\partial w}{\partial y}, \\
& \chi_{x}=\frac{\partial^{2} w}{\partial x^{2}}, \quad x_{y}=\frac{\partial^{2} w}{\partial y^{2}}, \quad \chi_{x y}=\frac{\partial^{2} w}{\partial x \partial y},
\end{aligned}
$$

where $\varepsilon_{x}^{0}$ and $\varepsilon_{y}^{0}$ are normal strains, $\gamma_{x y}^{0}$ is the shear strain at the middle surface of the equivalent shell, the changes of curvatures and twist of non-corrugated shell are denoted by $\chi_{x}, \chi_{y}, \chi_{x y}$, respectively, and $u=u(x, y), v=v(x, y), w=w(x, y)$ are the displacement terms in longitudinal, circumferential and inward directions, respectively.

The equivalent strains of equivalent shell thickness at a distance $z$ from the mid-surface are expressed as

$$
\varepsilon_{x}=\varepsilon_{x}^{0}-z \chi_{x}, \quad \varepsilon_{y}=\varepsilon_{y}^{0}-z \chi_{y}, \quad \gamma_{x y}=\gamma_{x y}^{0}-2 z \chi_{x y} .
$$

By using Equation (10), the deformation compatibility equation of FG-CNTRC cylindrical shell is determined as

$$
\varepsilon_{x, y y}^{0}+\varepsilon_{y, x x}^{0}-\gamma_{x y, x y}^{0}+\frac{1}{R} w_{, x x}-w_{, x y}^{2}+w_{, x x} w_{, x y}=0 .
$$

The nonlinear equilibrium equation system of the equivalent FG-CNTRC cylindrical shell in framework of the Donnell shell theory considered the von Karman nonlinearities is presented by [49]

$$
\begin{aligned}
& N_{x, x}+N_{x y, y}=0 \\
& N_{y, y}+N_{x y, x}=0, \\
& M_{x, x x}+2 M_{x y, x y}+M_{y, y y}+N_{x} w_{, x x}+2 N_{x y} w_{, x y}+N_{y} w_{, y y}+\frac{N_{y}}{R}+q_{0}=0 .
\end{aligned}
$$

Considering the first two equations of system (13), a stress function $\varphi$ may be introduced as

$$
N_{x}=\frac{\partial^{2} \varphi}{\partial y^{2}}, \quad N_{y}=\frac{\partial^{2} \varphi}{\partial x^{2}}, \quad N_{x y}=-\frac{\partial^{2} \varphi}{\partial x \partial y} .
$$

Substituting Equations (9) and (14) into the third equation of (13), the stability equation is rewritten as

$$
\begin{aligned}
& -w_{, x x x x} D_{11}-w_{, x x x y}\left(2 D_{16}+2 D_{61}\right)-w_{, x x y y}\left(D_{12}+4 D_{66}+D_{21}\right) \\
& -w_{, x y y y}\left(2 D_{62}+2 D_{26}\right)-w_{, y y y y} D_{22} \\
& +\varphi_{, y y} w_{, x x}+\varphi_{, x x} w_{, y y}-2 \varphi_{, x y} w_{, x y}+\frac{\varphi_{, x x}}{R}+q_{0}=0 .
\end{aligned}
$$

By using the constitutive relations (9) with the stress function expressions (14), the inverse relations can be established:

$$
\left\{\begin{array}{c}
\varepsilon_{x}^{0} \\
\varepsilon_{y}^{0} \\
\gamma_{x y}^{0}
\end{array}\right\}=\left\{\begin{array}{lll}
F_{11} & F_{12} & F_{16} \\
F_{21} & F_{22} & F_{26} \\
F_{61} & F_{62} & F_{66}
\end{array}\right\}\left\{\begin{array}{c}
\varphi, y y \\
\varphi, x x \\
-\varphi_{, x y}
\end{array}\right\},
$$

where

$$
\begin{aligned}
& F_{11}=\frac{A_{22} A_{66}-A_{62} A_{26}}{\Delta}, F_{12}=\frac{A_{61} A_{26}-A_{21} A_{66}}{\Delta}, F_{16}=\frac{A_{21} A_{62}-A_{61} A_{22}}{\Delta}, \\
& F_{21}=\frac{A_{62} A_{16}-A_{12} A_{66}}{\Delta}, F_{22}=\frac{A_{11} A_{66}-A_{61} A_{16}}{\Delta}, F_{26}=\frac{A_{61} A_{12}-A_{11} A_{62}}{\Delta}, \\
& F_{61}=\frac{A_{12} A_{26}-A_{22} A_{16}}{\Delta}, F_{62}=\frac{A_{21} A_{16}-A_{11} A_{26}}{\Delta}, F_{66}=\frac{A_{11} A_{22}-A_{21} A_{12}}{\Delta}, \\
& \Delta=\left(A_{11} A_{22} A_{66}+A_{12} A_{26} A_{61}+A_{21} A_{62} A_{16}\right)-\left(A_{16} A_{22} A_{61}+A_{12} A_{21} A_{66}+A_{11} A_{62} A_{26}\right) .
\end{aligned}
$$


Substituting Equation (16) into Equation (12), the rewritten deformation compatibility equation is as:

$$
\begin{aligned}
\varphi_{, x x x x} & F_{22}-\varphi_{, x x x y}\left(F_{26}+F_{62}\right)+\varphi_{, x x y y}\left(F_{12}+F_{21}+F_{66}\right) \\
& -\varphi_{, x y y y}\left(F_{16}+F_{61}\right)+\varphi_{, y y y y} F_{11}+\frac{1}{R} w_{, x x}-w_{, x y}^{2}+w_{, x x} w_{, x y}=0 .
\end{aligned}
$$

\section{Approximate Solution and Galerkin Procedure}

Suppose that a spiral corrugated FG-CNTRC cylindrical shell is simply supported and subjected to radial loads $q_{0}\left(\mathrm{~N} / \mathrm{m}^{2}\right)$. Thus the boundary conditions are of the form

$$
w=0, M_{x}=0, N_{x}=0, N_{x y}=0, \text { at } x=0 ; L .
$$

In this case, the deflection of the cylindrical shell can be chosen as a three-term solution form

$$
w=f_{0}+f_{1} \sin \frac{m \pi x}{L} \sin \frac{n y}{R}+f_{2} \sin ^{2} \frac{m \pi x}{L},
$$

in which $f_{0}$ is the pre-buckling uniform deflection, $f_{1}$ is the linear deflection amplitude, $f_{2}$ is the nonlinear deflection amplitude, $\sin \frac{m \pi x}{L} \sin \frac{n y}{R}$ is the linear buckling shape, $\sin ^{2} \frac{m \pi x}{L}$ is the nonlinear buckling shape in the axial direction, $m$ is the number of half waves and $n$ is the number of half waves in axial and circumferential directions, respectively.

It can be seen that the simply supported boundary condition at $x=0$ and $x=L$ is satisfied in the approximate sense.

Substituting Equation (19) into Equation (17) and solving the obtained equation for unknown $\varphi$, leads to

$$
\begin{gathered}
\varphi=\varphi_{1} \cos 2 \bar{\alpha} x+\varphi_{2} \cos 2 \bar{\beta} x+\varphi_{3} \sin \bar{\alpha} x \sin \bar{\beta} y+\varphi_{4} \sin 3 \bar{\alpha} x \sin \bar{\beta} y \\
+\varphi_{5} \cos \bar{\alpha} x \cos \bar{\beta} y+\varphi_{6} \cos 3 \bar{\alpha} x \cos \bar{\beta} y-\frac{1}{2} \sigma_{0 y} h x^{2}
\end{gathered}
$$

where

$$
\begin{aligned}
\varphi_{1} & =-\frac{1}{8} f_{2} \frac{1}{R \bar{\alpha}^{2} F_{22}}+\frac{1}{32} f_{1}^{2} \frac{\bar{\beta}^{2}}{\bar{\alpha}^{2} F_{22}}, \varphi_{2}=\frac{1}{32} f_{1}^{2} \frac{\bar{\alpha}^{2}}{\bar{\beta}^{2} F_{11}}, \varphi_{3}=\frac{f_{1} M_{1}+f_{1} f_{2} M_{2}}{M_{3}}, \\
\varphi_{4} & =f_{1} f_{2} \frac{M_{4}}{M_{5}}, \varphi_{5}=\frac{f_{1} M_{6}+f_{1} f_{2} M_{7}}{M_{3}}, \varphi_{6}=f_{1} f_{2} \frac{M_{8}}{M_{5}}, \\
\frac{m \pi}{L} & =\bar{\alpha}, \frac{n}{R}=\bar{\beta} \\
M_{1} & =\left[\bar{\alpha}^{4} F_{22}+\bar{\alpha}^{2} \bar{\beta}^{2}\left(F_{12}+F_{21}+F_{66}\right)+\bar{\beta}^{4} F_{11}\right] \frac{1}{R} \bar{\alpha}^{2}, \\
M_{2} & =-\bar{\alpha}^{2} \bar{\beta}^{2}\left[\bar{\alpha}^{4} F_{22}+\bar{\alpha}^{2} \bar{\beta}^{2}\left(F_{12}+F_{21}+F_{66}\right)+\bar{\beta}^{4} F_{11}\right], \\
M_{3} & =\left[\bar{\alpha}^{4} F_{22}+\bar{\alpha}^{2} \bar{\beta}^{2}\left(F_{12}+F_{21}+F_{66}\right)+\bar{\beta}^{4} F_{11}\right]^{2}-\left[\bar{\alpha}^{3} \bar{\beta}\left(F_{26}+F_{62}\right)+\bar{\alpha} \bar{\beta}^{3}\left(F_{16}+F_{61}\right)\right]^{2}, \\
M_{4} & =\bar{\alpha}^{2} \bar{\beta}^{2}\left[81 \bar{\alpha}^{4} F_{22}+9 \bar{\alpha}^{2} \bar{\beta}^{2}\left(F_{12}+F_{21}+F_{66}\right)+\bar{\beta}^{4} F_{11}\right], \\
M_{5} & =\left[81 \bar{\alpha}^{4} F_{22}+9 \bar{\alpha}^{2} \bar{\beta}^{2}\left(F_{12}+F_{21}+F_{66}\right)+\bar{\beta}^{4} F_{11}\right]^{2} \\
M_{6} & =-\bar{\alpha} \bar{\beta}\left[\bar{\alpha}^{2}\left(F_{26}+F_{62}\right)+\bar{\beta}^{2}\left(F_{16}+F_{61}\right)\right] \frac{1}{R} \bar{\alpha}^{2}, \\
M_{7} & =\bar{\alpha}^{3} \bar{\beta}^{3}\left[\bar{\alpha}^{2}\left(F_{26}+F_{62}\right)+\bar{\beta}^{2}\left(F_{16}+F_{61}\right)\right], \\
M_{8} & =-3 \bar{\alpha}^{3} \bar{\beta}^{3}\left[9 \bar{\alpha}^{2}\left(F_{26}+F_{62}\right)+\bar{\beta}^{2}\left(F_{16}+F_{61}\right)\right] .
\end{aligned}
$$

Substituting the deflection form (19) and stress function (20) into Equation (15) and then applying the Galerkin method in the ranges $0 \leq x \leq L$ and $0 \leq y \leq 2 \pi R$ leads to

$$
-2 \sigma_{0 y} \frac{h}{R}+2 q_{0}=0,
$$




$$
\begin{gathered}
f_{1}\left(N_{1}+\sigma_{0 y} h \frac{n^{2}}{R^{2}}\right)+f_{1} f_{2} N_{2}+f_{1} f_{2}^{2} N_{3}+f_{1}^{3} N_{4}=0, \\
f_{1}^{2} N_{5}+f_{1}^{2} f_{2} N_{6}+f_{2} N_{7}-\frac{\sigma_{0 y} h}{R}+q_{0}=0
\end{gathered}
$$

where

$$
\begin{aligned}
& N_{1}=-\frac{M_{1}}{M_{3}} \frac{\bar{\alpha}^{2}}{R}-\left[\bar{\alpha}^{4} D_{11}+\bar{\alpha}^{2} \bar{\beta}^{2}\left(D_{12}+4 D_{66}+D_{21}\right)+\bar{\beta}^{4} D_{22}\right], \\
& N_{2}=-\frac{M_{2}}{M_{3}} \frac{\bar{\alpha}^{2}}{R}+\frac{M_{1}}{M_{3}} \bar{\alpha}^{2} \bar{\beta}^{2}+\frac{1}{4 F_{22}} \frac{\bar{\beta}^{2}}{R}, N_{3}=\frac{M_{2}}{M_{3}} \bar{\alpha}^{2} \bar{\beta}^{2}-\frac{M_{4}}{M_{5}} \bar{\alpha}^{2} \bar{\beta}^{2}, \\
& N_{4}=-\frac{1}{16 F_{12}} \bar{\alpha}^{4}-\frac{1}{16 F_{22}} \bar{\beta}^{4}, N_{5}=\frac{1}{16 F_{22}} \frac{\bar{\beta}^{2}}{R}+\frac{1}{2} \frac{M_{1}}{M_{3}} \bar{\alpha}^{2} \bar{\beta}^{2}, \\
& N_{6}=\frac{1}{2}\left(\frac{M_{2}}{M_{3}}-\frac{M_{4}}{M_{5}}\right) \bar{\alpha}^{2} \bar{\beta}^{2}, \quad N_{7}=\frac{F_{21}}{F_{22}} \frac{\bar{\alpha}^{2}}{R}-\frac{1}{4 F_{22} R^{2}}-4 \bar{\alpha}^{4} D_{11} .
\end{aligned}
$$

For the revolution shell characteristics, the corrugated FG-CNTRC cylindrical shell should satisfy the circumferential closed condition, expressed as [5]

$$
\int_{0}^{L} \int_{0}^{2 \pi R}\left(\varepsilon_{y}^{0}+\frac{w}{R}-\frac{1}{2} w_{, y}^{2}\right) d x d y=0 .
$$

Using Equations (16), (19), (23) and (24), this integral becomes

$$
-2 F_{22} \sigma_{0 y} h+2 \frac{f_{0}}{R}+\frac{f_{2}}{R}-\frac{1}{4} f_{1}^{2} \frac{n^{2}}{R^{2}}=0 .
$$

Eliminating $\sigma_{0 y}$ from Equations (21)-(23) and the condition of closed form (25), leads to

$$
q_{0}=-f_{2}^{2} \frac{N_{3} R}{n^{2}}-f_{2} \frac{N_{2} R}{n^{2}}+\frac{f_{2}}{f_{2} N_{6}+N_{5}} \frac{N_{4} N_{7} R}{n^{2}}-\frac{N_{1} R}{n^{2}} .
$$

Ignoring the nonlinear term $f_{2}$ in Equation (26), leads to

$$
q_{0}^{\text {upper }}=-\frac{N_{1}}{N_{4} N_{7}}
$$

where $q_{0}^{\text {upper }}$ is the linear upper static buckling load of corrugated and non-corrugated FG-CNTRC cylindrical shells.

The linear static critical buckling loads of spiral corrugated FG-CNTRC cylindrical shells are determined by conditions $q_{c r}=\min q_{0}^{u p p e r}$ vs. $(m, n)$.

The maximal deflection of the shell can be calculated by taking the sum of three amplitude terms, as

$$
W_{\max }=f_{0}+f_{1}+f_{2} .
$$

By using Equations (21)-(23), Equation (28) is rewritten by respecting to nonlinear deflection amplitude $f_{2}$, as

$$
W_{\max }=-\frac{N_{7} n^{2} f_{2}}{8 R\left(f_{2} N_{6}+N_{5}\right)}+\frac{f_{2}}{2}+\left(-\frac{f_{2} N_{7}}{f_{2} N_{6}+N_{5}}\right)^{\frac{1}{2}}+F_{22} R^{2} q_{0} .
$$

The postbuckling curves of spiral corrugated FG-CNTRC cylindrical shells may be obtained by combining Equation (26) and Equation (29).

\section{Numerical Investigations and Remarks}

In this paper, the accuracy of the present analytical approach for the critical buckling loads of non-corrugated FG-CNTRC cylindrical shells under radial loads are compared with the results reported 
by Shen [22]. In these comparisons, the SWCNT is reinforced in the longitudinal direction of shells. As can be seen in Table 1, the very small differences between the present results with the corresponding results of Shen [22] are recognized.

Table 1. Comparisons of critical buckling loads of non-corrugated FG-CNTRC cylindrical shells subjected to radial loads (in $\mathrm{kPa})\left(h=0.001 \mathrm{~m}, R / h=100, T=300 \mathrm{~K}, \bar{Z}=\frac{L^{2}}{R h}\right)$.

\begin{tabular}{|c|c|c|c|c|c|}
\hline & & & $\bar{Z}=100$ & $\bar{Z}=300$ & $\bar{Z}=500$ \\
\hline \multirow{4}{*}{$V_{\mathrm{CNT}}^{*}=0.12$} & \multirow{2}{*}{ UD } & Shen [22] & $42.68(1,10)$ * & $23.40(1,8)$ & $18.18(1,7)$ \\
\hline & & Present & $42.82(1,10)$ & $23.45(1,8)$ & $18.51(1,7)$ \\
\hline & \multirow{2}{*}{ FG-X } & Shen [22] & $49.48(1,10)$ & $25.60(1,8)$ & $19.91(1,7)$ \\
\hline & & Present & $48.65(1,10)$ & $25.37(1,8)$ & $19.78(1,7)$ \\
\hline \multirow{4}{*}{$V_{\mathrm{CNT}}^{*}=0.17$} & \multirow{2}{*}{ UD } & Shen [22] & $70.06(1,10)$ & $38.98(1,8)$ & $30.81(1,7)$ \\
\hline & & Present & $70.28(1,10)$ & $39.06(1,8)$ & $30.85(1,7)$ \\
\hline & \multirow{2}{*}{ FG-X } & Shen [22] & $82.76(1,10)$ & $43.83(1,8)$ & $34.15(1,7)$ \\
\hline & & Present & $81.44(1,10)$ & $43.47(1,8)$ & $33.94(1,7)$ \\
\hline \multirow{4}{*}{$V_{C N T}^{*}=0.28$} & \multirow{2}{*}{ UD } & Shen [22] & $84.34(1,10)$ & $45.11(1,8)$ & $35.56(1,7)$ \\
\hline & & Present & $84.67(1,10)$ & $45.22(1,8)$ & $35.62(1,7)$ \\
\hline & \multirow{2}{*}{ FG-X } & Shen [22] & $109.42(1,10)$ & $55.84(1,8)$ & $43.24(1,7)$ \\
\hline & & Present & $108.68(1,10)$ & $56.01(1,8)$ & $43.44(1,7)$ \\
\hline
\end{tabular}

* the numbers in the parentheses denote the buckling mode $(m, n)$.

Numerical examples are given to investigate the nonlinear buckling and postbuckling behavior of spiral corrugated FG-CNTRC circular cylindrical shells under radial loads. The mechanic properties of the isotropic Poly methyl methacrylate matrix (PMMA) material are considered to be $v^{m}=0.34$, $\alpha^{m}=45(1+0.0005 \Delta T) \times 10^{-6} / \mathrm{K}$ and $E^{m}=(3.52-0.0034 T) \times 10^{12} \mathrm{~Pa}$ in which $T$ is the temperature of the environment. The CNT is reinforced in the circumferential direction of shells. The mechanic properties of CNT are presented in the work of Shen [23] as follows:

$$
\begin{aligned}
& v_{12}^{C N T}=0.175 \\
& E_{11}^{C N T}=\left(6.18387-0.00286 T+4.22867 \times 10^{-6} T^{2}-2.2724 \times 10^{-9} T^{3}\right) \times 10^{12} \mathrm{~Pa}, \\
& E_{22}^{C N T}=\left(7.75348-0.00358 T+5.30057 \times 10^{-6} T^{2}-2.84868 \times 10^{-9} T^{3}\right) \times 10^{12} \mathrm{~Pa}, \\
& G_{12}^{C N T}=\left(1.80126+7.7845 \times 10^{-4} T-1.1279 \times 10^{-6} T^{2}+4.93484 \times 10^{-10} T^{3}\right) \times 10^{12} \mathrm{~Pa}, \\
& \alpha_{11}^{C N T}=\left(-1.12148+0.02289 T-2.88155 \times 10^{-5} T^{2}+1.13253 \times 10^{-8} T^{3}\right) \times 10^{-6} / \mathrm{K}, \\
& \alpha_{22}^{C N T}=\left(5.43874-9.95498 \times 10^{-4} T+3.13525 \times 10^{-7} T^{2}-3.56332 \times 10^{-12} T^{3}\right) \times 10^{-6} / \mathrm{K} .
\end{aligned}
$$

The coefficients $\eta_{1}$ and $\eta_{2}$ are estimated by using the elastic constants $E_{11}$ and $E_{22}$ of CNTRC shells and can be applied with the rule of mixture to those from molecular dynamics simulations, as reported by Han and Elliott [50]. According to results of Shen and Xiang [24], $\eta_{1}=0.137, \eta_{2}=1.022$ applies for the case of $V_{C N T}^{*}=0.12 ; \eta_{1}=0.142, \eta_{2}=1.626$ applies for the case of $V_{C N T}^{*}=0.17$; and $\eta_{1}=0.141, \eta_{2}=1.585$ applies for the case of $V_{C N T}^{*}=0.28$ and $\eta_{3}: \eta_{2}=0.7: 1$.

The FG-CNTRC corrugated cylindrical shells are considered with the geometrical parameters given by $L=0.75 \mathrm{~m}, R=0.5 \mathrm{~m}$, and $h=1 \mathrm{~mm}$.

In this paper, the numerical results are investigated at room temperature $(T=300 \mathrm{~K})$.

Table 2 presents the critical buckling loads $q_{0}^{c r}$ for non-corrugated and corrugated FG-CNTRC cylindrical shells with these three types of distribution (UD, FG-X and FG-O distributions), under radial loads. To validate the effect of corrugations, the thickness of non-corrugated cylindrical shell is calculated so that the material quantity of non-corrugated shell is equal to the corrugated shell, respectively. 
Table 2. Critical buckling loads of non-corrugated and corrugated FG-CNTRC cylindrical shells (in $\mathrm{MPa}$ ).

\begin{tabular}{lccc}
\hline \multicolumn{1}{c}{ UD } & FG-X & FG-O \\
\hline Round corrugated cylindrical shells $V_{C N T}^{*}=0.12, r=0.0075 \mathrm{~m}, d=0.003 \mathrm{~m}$. & \\
Non corrugated & $0.0207(1,5)^{*}$ & $0.0267(1,5)$ & $0.0124(1,6)$ \\
Ring corrugated & $0.1668(1,1)$ & $0.1732(1,1)$ & $0.1625(1,1)$ \\
$N=1$ & $0.1673(1,1)$ & $0.1737(1,1)$ & $0.1630(1,1)$ \\
$N=3$ & $0.1716(1,1)$ & $0.1782(1,1)$ & $0.1672(1,1)$ \\
$N=5$ & $0.1803(1,1)$ & $0.1874(1,1)$ & $0.1756(1,1)$ \\
Maximal critical buckling load & $0.8079(1,3,59)^{* *}$ & $0.8083(1,3,59)$ & $0.8076(1,3,59)$ \\
\hline Trapezoidal corrugated cylindrical shells $V_{C N T}^{*}=0.12, c=0.015 \mathrm{~m}, f=0.0075 \mathrm{~m}, \alpha=\pi / 3$ \\
Non corrugated & $0.0116(1,6)$ & $0.0160(1,6)$ & $0.0073(1,6)$ \\
Ring corrugated & $0.1419(1,2)$ & $0.1422(1,2)$ & $0.1417(1,2)$ \\
$N=1$ & $0.1419(1,2)$ & $0.1423(1,2)$ & $0.1417(1,2)$ \\
$N=3$ & $0.1424(1,2)$ & $0.1428(1,2)$ & $0.1422(1,2)$ \\
$N=5$ & $0.1434(1,2)$ & $0.1437(1,2)$ & $0.1432(1,2)$ \\
Maximal critical buckling load & $0.3544(1,3,59)$ & $0.3548(1,3,59)$ & $0.3541(1,3,58)$ \\
\hline
\end{tabular}

${ }^{*}$ the numbers in the parentheses denote the buckling mode $(m, n)$; ${ }^{* *}$ the numbers in the parentheses denote the buckling mode and wave number of corrugation of a loop coil $(m, n, N)$.

The results for a UD-CNTRC cylindrical shell are also listed in direct comparison. It can be seen that the buckling loads of FG-X type shells are larger and the buckling loads of FG-O type shells are smaller than those of the UD-CNTRC cylindrical shells. Especially, the buckling loads of corrugated cylindrical shells are greater than those of non-corrugated shells. The critical buckling loads of spiral stiffened shells are larger than those of ring corrugated shells and they significantly increase when the wave number of corrugation of a loop coil increases. The maximal critical buckling loads are reached at the very large wave number of corrugation of a loop coil.

Figures 2 and 3 present the postbuckling load-deflection curves for ring and spiral corrugated CNTRC cylindrical shells for three cases of distribution (UD, $\mathrm{X}$ and $\mathrm{O}$ distributions) subjected to radial loads. The results for UD-CNTRC cylindrical shells are also included for direct comparison. Clearly, the postbuckling curve of FG-X distribution shells is highest, the postbuckling curve of FG-O distribution shells is lowest, and the postbuckling curve of the UD-CNTRC cylindrical shell is in the middle of those of FG-X and FG-O distribution shells.

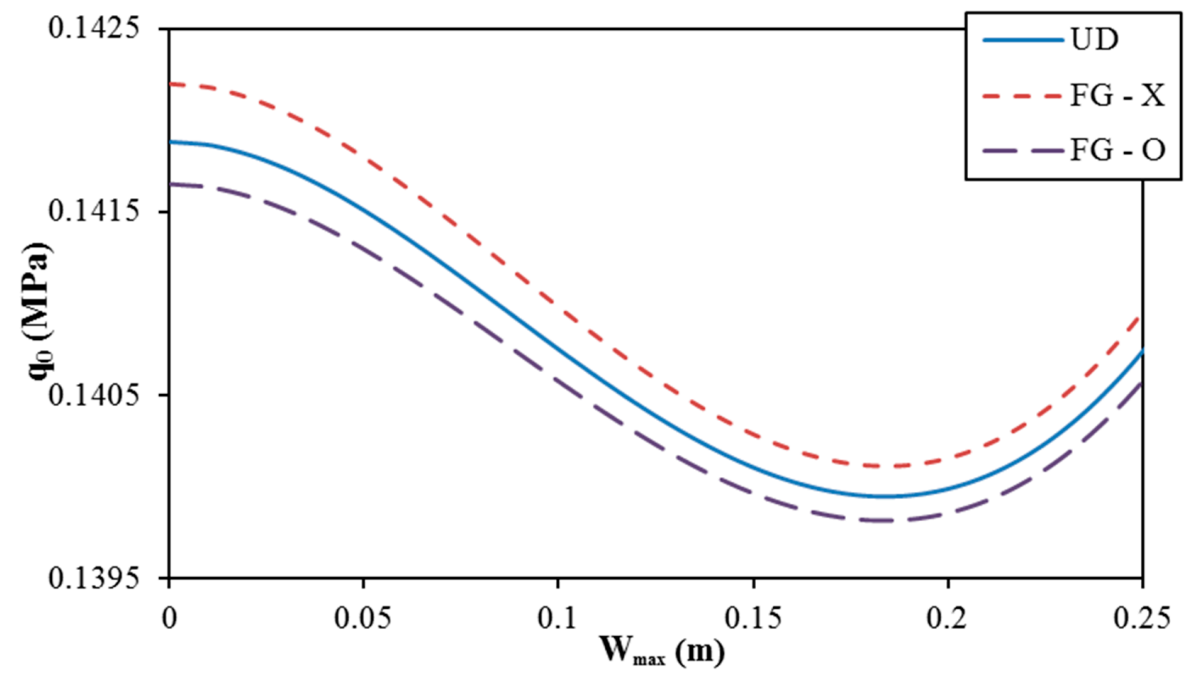

Figure 2. Effect of carbon nanotube (CNT) reinforcement type on the postbuckling curve of ring corrugated cylindrical shells (trapezoidal corrugation, $V_{C N T}^{*}=0.12, c=0.015 \mathrm{~m}, f=0.0075 \mathrm{~m}, \alpha=\pi / 3$ ). 


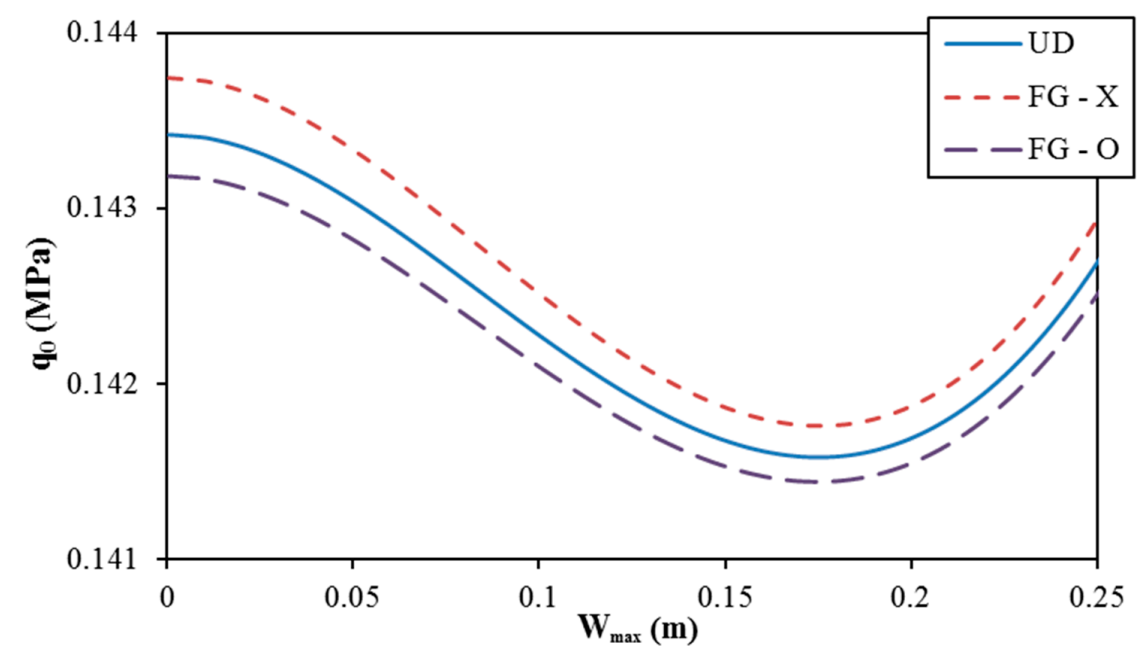

Figure 3. Effect of CNT reinforcement type on the postbuckling curve of spiral corrugated cylindrical shells (trapezoidal corrugation, $V_{C N T}^{*}=0.12, c=0.015 \mathrm{~m}, f=0.0075 \mathrm{~m}, \alpha=\pi / 3, N=5$ ).

Tables 3 and 4 show the effect of geometrical properties of corrugation and CNT volume fraction $V_{C N T}^{*}$ on the critical buckling load of round and trapezoidal corrugated cylindrical shells, respectively. As can be seen, a very large effect of CNT reinforcement on the critical buckling of shells is recognized. The critical buckling load increases when the volume fraction of CNT $V_{C N T}^{*}$ increases. The effect of geometrical parameters of round and trapezoidal corrugation on the critical buckling load of spiral corrugated FG-CNTRC cylindrical shells is also presented in these tables. Clearly, the critical buckling loads of corrugated cylindrical shells increase when the geometrical parameters of corrugations increase.

Table 3. Effects of geometrical parameters of corrugation and CNT volume fraction $V_{C N T}^{*}$ on the critical buckling of corrugated uniformly distributed carbon nanotube-reinforced composite (UD-CNTRC) cylindrical shells (round corrugation) (in MPa).

\begin{tabular}{|c|c|c|c|c|c|c|c|}
\hline \multirow{2}{*}{$V_{C N T}^{*}$} & \multirow{2}{*}{$r(\mathrm{~m})$} & \multirow{2}{*}{$d(\mathrm{~m})$} & \multirow{2}{*}{$\begin{array}{c}\text { Non } \\
\text { Corrugated }\end{array}$} & \multirow{2}{*}{$\begin{array}{c}\text { Ring } \\
\text { Corrugated }\end{array}$} & \multicolumn{3}{|c|}{ Spiral Corrugated } \\
\hline & & & & & $N=1$ & $N=3$ & $N=5$ \\
\hline \multirow{3}{*}{0} & 0.005 & 0.002 & $0.0016(1,9)$ & $0.0072(1,2)$ & $0.0072(1,2)$ & $0.0073(1,2)$ & $0.0073(1,2)$ \\
\hline & 0.0075 & 0.003 & $0.0016(1,9)$ & $0.0108(1,2)$ & $0.0108(1.2)$ & $0.0109(1,2)$ & $0.0110(1,2)$ \\
\hline & 0.01 & 0.004 & $0.0016(1,9)$ & $0.0176(1,2)$ & $0.0176(1,2)$ & $0.0177(1,2)$ & $0.0180(1,2)$ \\
\hline \multirow{3}{*}{0.12} & 0.005 & 0.002 & $0.0207(1,5)$ & $0.1450(1,2)$ & $0.1450(1,2)$ & $0.1452(1,2)$ & $0.1457(1,2)$ \\
\hline & 0.0075 & 0.003 & $0.0207(1,5)$ & $0.1668(1,1)$ & $0.1673(1,1)$ & $0.1716(1,1)$ & $0.1803(1,1)$ \\
\hline & 0.01 & 0.004 & $0.0207(1,5)$ & $0.1913(1,1)$ & $0.1922(1,1)$ & $0.1996(1,1)$ & $0.2149(1,1)$ \\
\hline \multirow{3}{*}{0.17} & 0.005 & 0.002 & $0.0311(1,6)$ & $0.2119(1,2)$ & $0.2119(1,2)$ & $0.2123(1,2)$ & $0.2129(1,2)$ \\
\hline & 0.0075 & 0.003 & $0.0311(1,6)$ & $0.2630(1,1)$ & $0.2638(1,1)$ & $0.2707(1,1)$ & $0.2848(1,1)$ \\
\hline & 0.01 & 0.004 & $0.0311(1,6)$ & $0.2900(1,1)$ & $0.2915(1,1)$ & $0.3030(1,1)$ & $0.3267(1,1)$ \\
\hline \multirow{3}{*}{0.28} & 0.005 & 0.002 & $0.0449(1,5)$ & $0.3410(1,2)$ & $0.3411(1,2)$ & $0.3416(1,2)$ & $0.3427(1,2)$ \\
\hline & 0.0075 & 0.003 & $0.0449(1,5)$ & $0.3531(1,1)$ & $0.3542(1,1)$ & $0.3630(1,1)$ & $0.3809(1,1)$ \\
\hline & 0.01 & 0.004 & $0.0449(1,5)$ & $0.4286(1,1)$ & $0.4306(1,1)$ & $0.4468(1,1)$ & $0.4799(1,1)$ \\
\hline
\end{tabular}


Table 4. Effects of geometrical parameters of corrugation and CNT volume fraction $V_{C N T}^{*}$ on the critical buckling of UD-CNTRC cylindrical shells (trapezoidal corrugation, $\alpha=\pi / 3$ ) (in MPa).

\begin{tabular}{|c|c|c|c|c|c|c|c|}
\hline \multirow{2}{*}{$V_{C N T}^{*}$} & \multirow{2}{*}{$c(\mathrm{~m})$} & \multirow{2}{*}{$f(\mathrm{~m})$} & \multirow{2}{*}{$\begin{array}{c}\text { Non } \\
\text { Corrugated }\end{array}$} & \multirow{2}{*}{$\begin{array}{c}\text { Ring } \\
\text { Corrugated }\end{array}$} & \multicolumn{3}{|c|}{ Spiral Corrugated } \\
\hline & & & & & $N=1$ & $N=3$ & $N=5$ \\
\hline \multirow{3}{*}{0} & 0.01 & 0.005 & $0.0009(1,9)$ & $0.0048(1,3)$ & $0.0048(1,3)$ & $0.0048(1,3)$ & $0.0048(1,3)$ \\
\hline & 0.015 & 0.0075 & $0.0009(1,9)$ & $0.0072(1,2)$ & $0.0072(1,2)$ & $0.0073(1,2)$ & $0.0074(1,2)$ \\
\hline & 0.02 & 0.01 & $0.0009(1,9)$ & $0.0091(1,2)$ & $0.0091(1,2)$ & $0.0092(1,2)$ & $0.0093(1,2)$ \\
\hline \multirow{3}{*}{0.12} & 0.01 & 0.005 & $0.0116(1,6)$ & $0.0688(1,2)$ & $0.0688(1,2)$ & $0.0689(1,2)$ & $0.0691(1,2)$ \\
\hline & 0.015 & 0.0075 & $0.0116(1,6)$ & $0.1419(1,2)$ & $0.1419(1,2)$ & $0.1424(1,2)$ & $0.1434(1,2)$ \\
\hline & 0.02 & 0.01 & $0.0116(1,6)$ & $0.1741(1,1)$ & $0.1752(1,1)$ & $0.1837(1,1)$ & $0.2018(1,1)$ \\
\hline \multirow{3}{*}{0.17} & 0.01 & 0.005 & $0.0175(1,6)$ & $0.1018(1,2)$ & $0.1018(1,2)$ & $0.1020(1,2)$ & $0.1024(1,2)$ \\
\hline & 0.015 & 0.0075 & $0.0175(1,6)$ & $0.2074(1,2)$ & $0.2075(1,2)$ & $0.2082(1,2)$ & $0.2097(1,2)$ \\
\hline & 0.02 & 0.01 & $0.0175(1,6)$ & $0.2796(1,1)$ & $0.2813(1,1)$ & $0.2953(1,1)$ & $0.3248(1,1)$ \\
\hline \multirow{3}{*}{0.28} & 0.01 & 0.005 & $0.0262(1,6)$ & $0.1592(1,2)$ & $0.1592(1,2)$ & $0.1595(1,2)$ & $0.1600(1,2)$ \\
\hline & 0.015 & 0.0075 & $0.0262(1,6)$ & $0.3337(1,2)$ & $0.3338(1,2)$ & $0.3350(1,2)$ & $0.3373(1,2)$ \\
\hline & 0.02 & 0.01 & $0.0262(1,6)$ & $0.3586(1,1)$ & $0.3607(1,1)$ & $0.3778(1,1)$ & $0.4138(1,1)$ \\
\hline
\end{tabular}

Figure 4 shows the effect of CNT volume fraction $V_{C N T}^{*}=0.12 ; 0.17$ and 0.28 on the postbuckling curve of ring corrugated UD-CNTRC cylindrical shells and corresponding non-corrugated UD-CNTRC cylindrical shells subjected to radial loads. As can be seen the increase of CNT volume fraction $V_{C N T}^{*}$ yields an increase of the critical buckling load and postbuckling strength of shells.

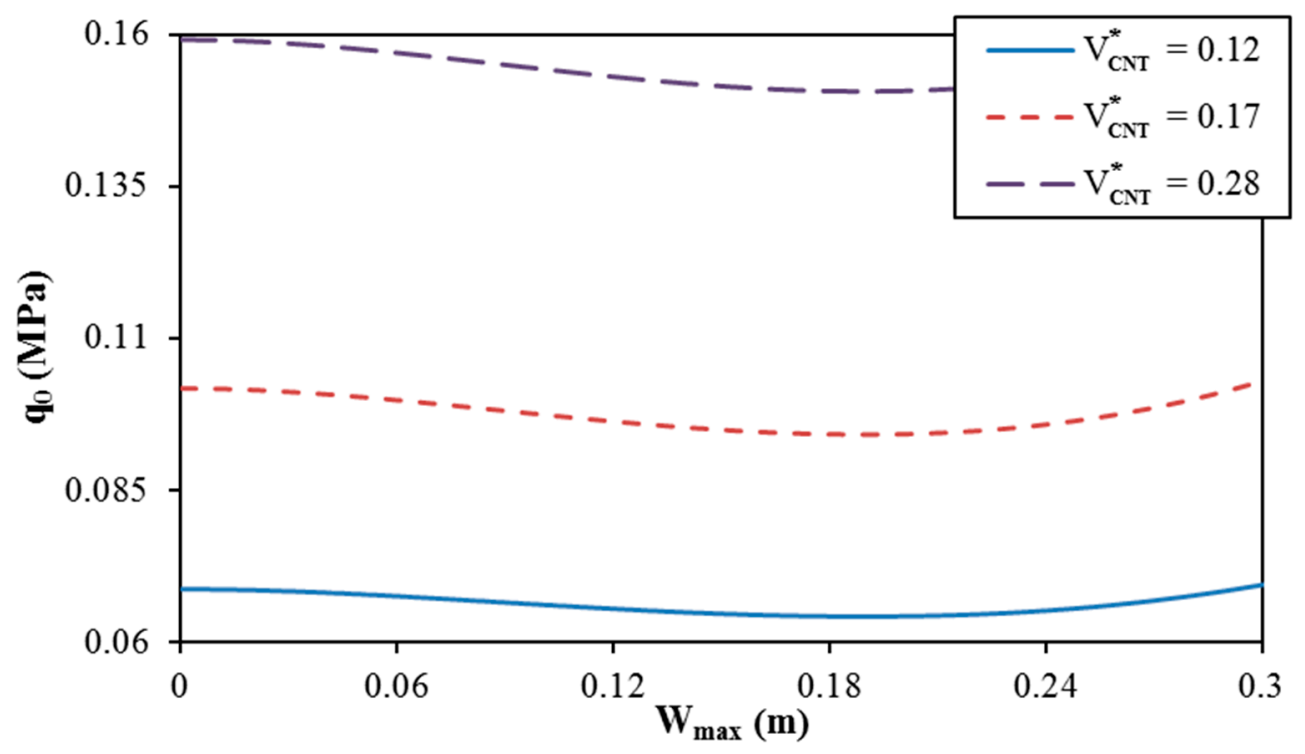

(a) Ring corrugated shells

Figure 4. Cont. 


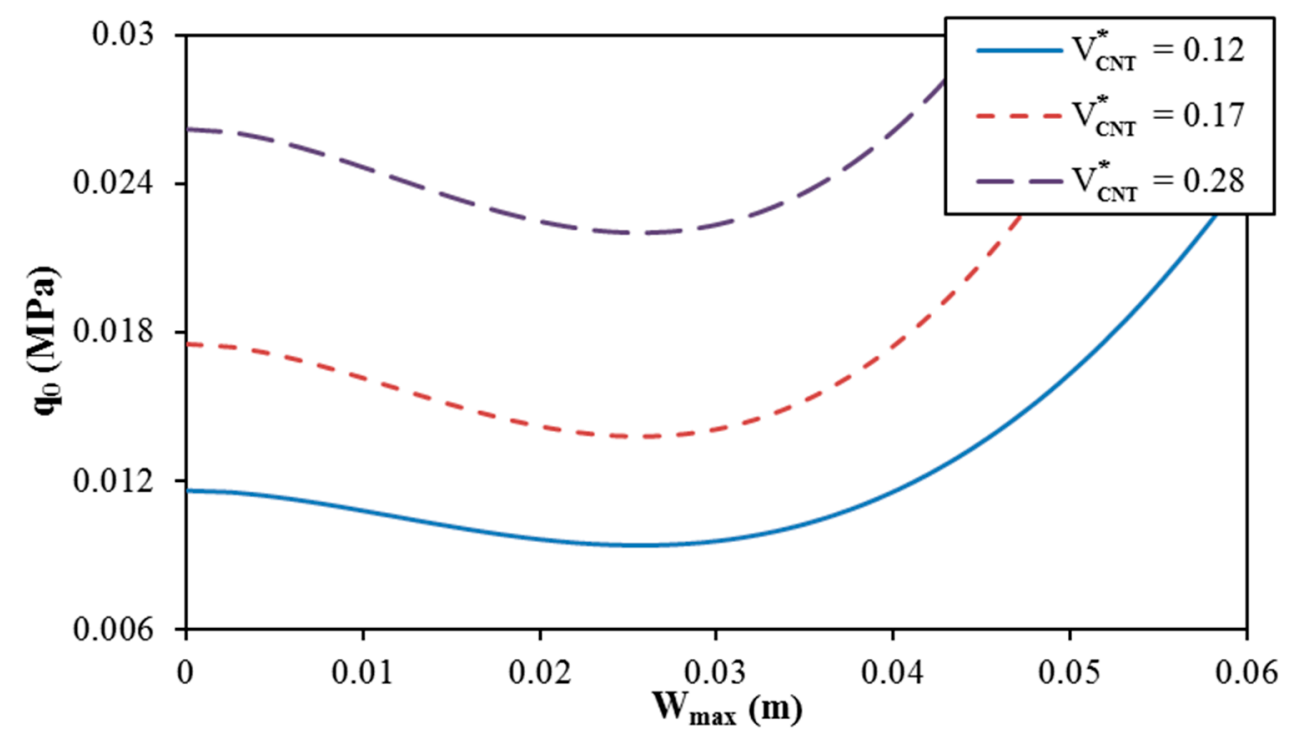

(b) Corresponding non-corrugated shells

Figure 4. Effect of CNT volume fraction $V_{C N T}^{*}$ on the postbuckling curve of ring corrugated UD-CNTRC cylindrical shells and corresponding non-corrugated UD-CNTRC cylindrical shells (trapezoidal corrugation, $c=0.01 \mathrm{~m}, f=0.005 \mathrm{~m}, \alpha=\pi / 3)$.

A comparison of the postbuckling curve of ring and spiral corrugated UD-CNTRC cylindrical shells in two cases, round corrugation and trapezoidal corrugation, is presented in Figures 5 and 6. Spiral corrugation is considered with the wave number of corrugation of a loop coil $N=5$ and $N=10$. Clearly, the wave number of corrugation of a loop coil strongly influences the postbuckling behavior of cylindrical shells and an usual change is obtained when the wave number of corrugation of a loop coil changes.

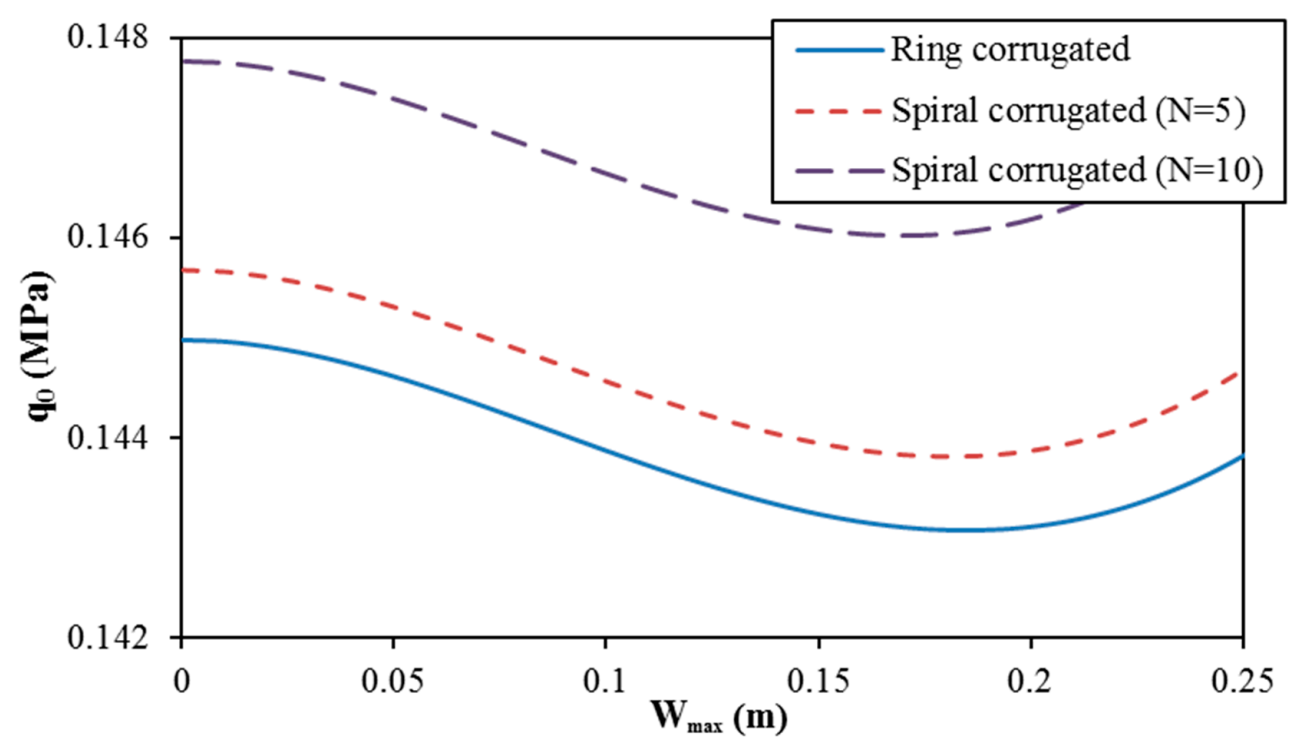

Figure 5. Postbuckling curves of ring and spiral corrugated UD-CNTRC cylindrical shells (round corrugation, $V_{C N T}^{*}=0.12, r=0.005 \mathrm{~m}, d=0.002 \mathrm{~m}$ ). 


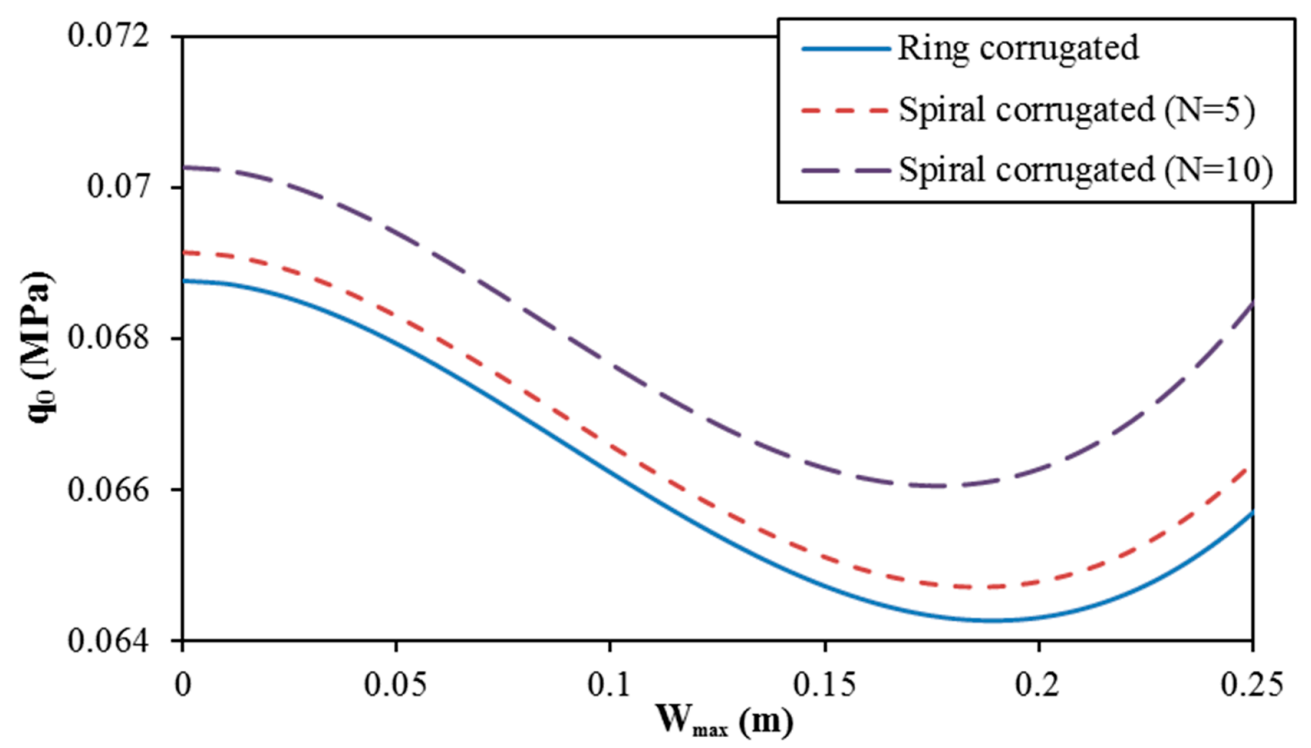

Figure 6. Postbuckling curves of ring and spiral corrugated UD-CNTRC cylindrical shells (trapezoidal corrugation, $\left.V_{C N T}^{*}=0.12, c=0.01 \mathrm{~m}, f=0.005 \mathrm{~m}, \alpha=\pi / 3\right)$.

The effect of geometrical parameters of corrugation on the postbuckling curve of spiral corrugated UD-CNTRC cylindrical shells is presented in Figures 7 and 8. The results show that geometrical parameters of corrugation strongly influence the postbuckling curve of cylindrical shells and an unusual change is recognized when the geometrical parameters of corrugations changes.

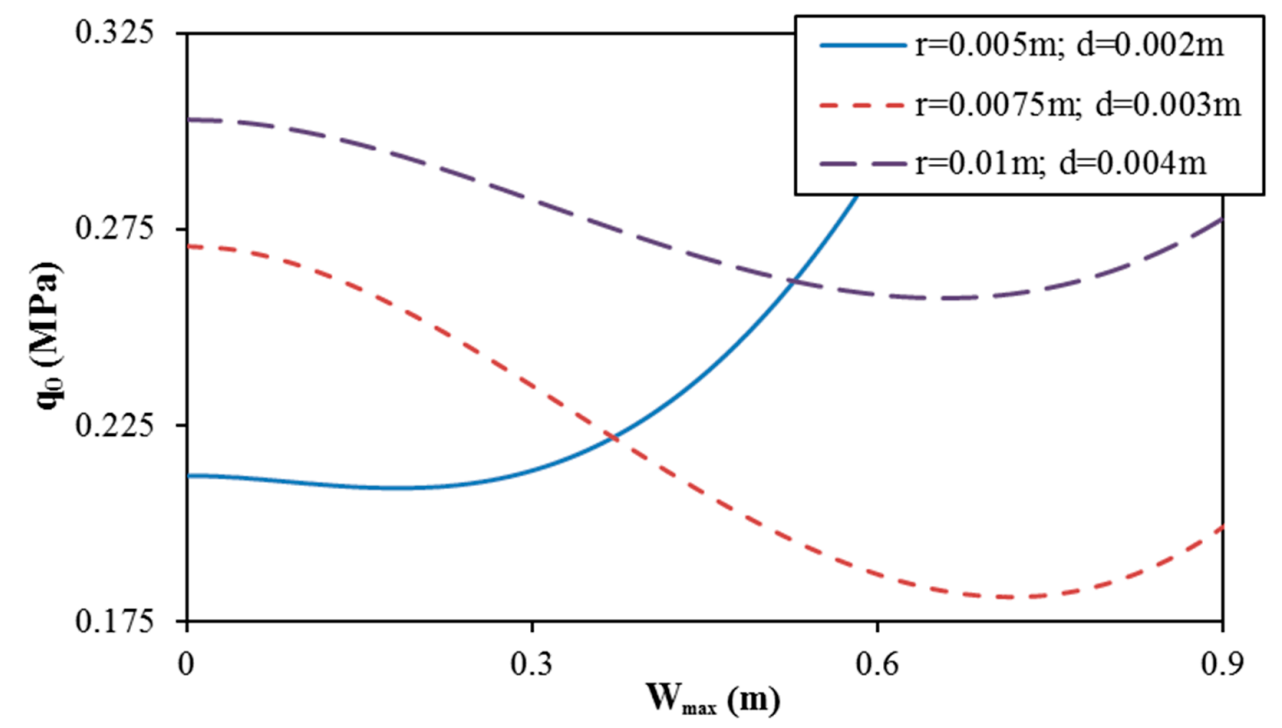

Figure 7. Effect of geometrical parameters of corrugation on the postbuckling curve of spiral corrugated UD-CNTRC cylindrical shells (round corrugation, $V_{C N T}^{*}=0.17, N=3$. 


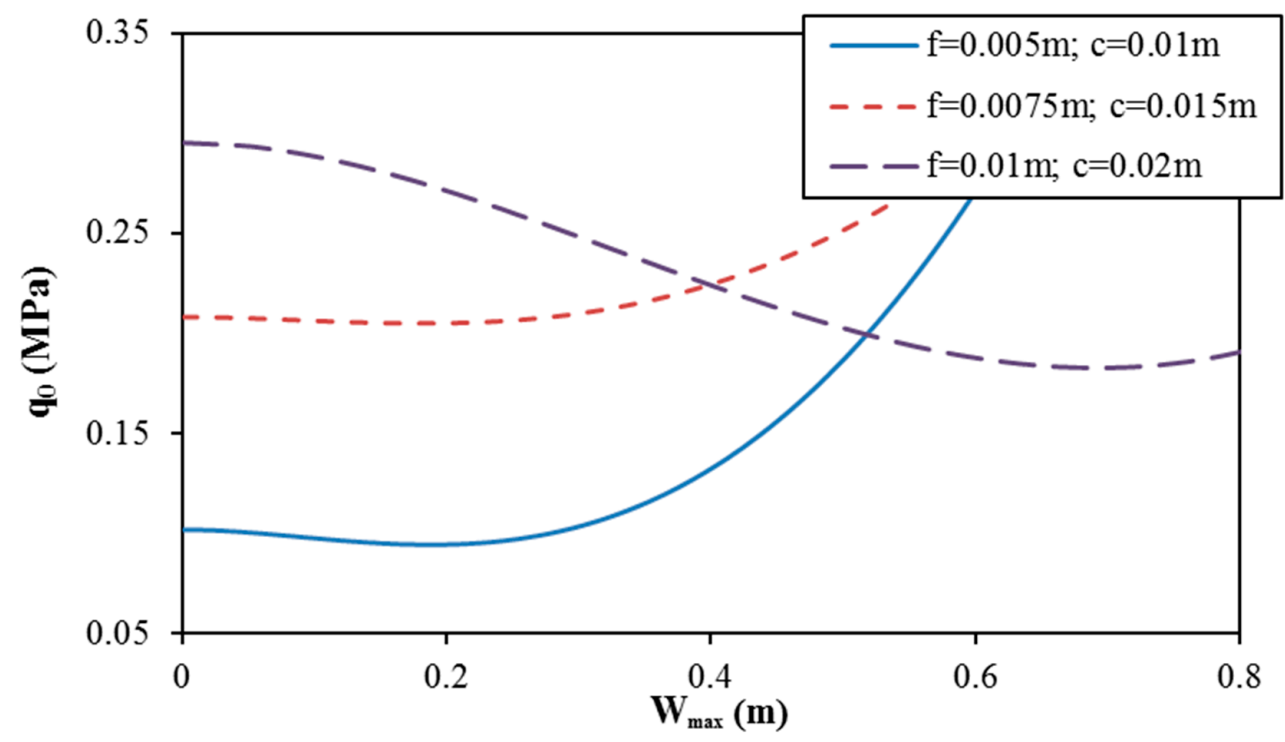

Figure 8. Effect of geometrical parameters of corrugation on the postbuckling curve of spiral corrugated UD-CNTRC cylindrical shells (trapezoidal corrugation, $V_{C N T}^{*}=0.17, N=3$.

\section{Conclusions}

In the present paper, the nonlinear global buckling of spiral corrugated FG-CNTRC cylindrical shells subjected to radial loads is derived by using an equivalent model of corrugation structures of Xia et al. [48] and the coordinate transformation procedure. Especially, the very large effects of corrugation are validated by comparing the critical buckling loads of corrugated shells with those of non-corrugated shells.

Some significant results that may be obtained from this paper are:

(1) The corrugated FG-CNTRC cylindrical shells are homogenized by equivalent non-corrugated FG-CNTRC cylindrical shells.

(2) The critical buckling load of a corrugated FG-CNTRC cylindrical shell is must larger than that of a non-corrugated FG-CNTRC cylindrical shell.

(3) Geometrical properties of two types of corrugations and material parameters of FG-CNTRC shells significantly influence the linear and nonlinear buckling responses of shells.

Author Contributions: Formal analysis, T.D.D.; Investigation, T.H.V. and N.L.L.; Methodology, H.N.V., N.-T.T. and T.P.N.; Validation, T.T.X.N.; All authors have read and agreed to the published version of the manuscript.

Funding: This research received no external funding.

Conflicts of Interest: The authors declare no conflict of interest.

\section{References}

1. Shen, H.S. Postbuckling analysis of axially-loaded functionally graded cylindrical shells in thermal environments. Compos. Sci. Technol. 2002, 62, 977-987. [CrossRef]

2. Shen, H.S. Postbuckling analysis of pressure-loaded functionally graded cylindrical shells in thermal environments. Eng. Struct. 2003, 25, 487-497. [CrossRef]

3. Shen, H.S.; Xiang, Y. Postbuckling of pressure-loaded piezolaminated cylindrical shells with temperature dependent properties. Int. J. Struct. Stab. Dyn. 2007, 7, 1-22. [CrossRef]

4. Huang, H.; Han, Q. Buckling of imperfect functionally graded cylindrical shells under axial compression. Eur. J. Mech. A Solids 2008, 27, 1026-1036. [CrossRef]

5. Huang, H.; Han, Q. Nonlinear elastic buckling and postbuckling of axially compressed functionally graded cylindrical shells. Int. J. Mech. Sci. 2009, 51, 500-507. [CrossRef] 
6. Sofiyev, A.H.; Schnak, E. The stability of functionally graded cylindrical shells under linearly increasing dynamic torsional loading. Eng. Struct. 2004, 26, 1321-1331. [CrossRef]

7. Sofiyev, A.H. Buckling analysis of FGM circular shells under combined loads and resting on the Pasternak type elastic foundation. Mech. Res. Commun. 2010, 37, 539-544. [CrossRef]

8. Sofiyev, A.H. The buckling of FGM truncated conical shells subjected to combined axial tension and hydrostatic pressure. Compos. Struct. 2010, 92, 488-498. [CrossRef]

9. Sofiyev, A.H. The buckling of FGM truncated conical shells subjected to axial compressive load and resting on Winkler-Pasternak foundations. Int. J. Press. Vessel. Pip. 2010, 87, 753-761. [CrossRef]

10. Sofiyev, A.H. On the vibration and stability of clamped FGM conical shells under external loads. J. Compos. Mater. 2011, 45, 771-788. [CrossRef]

11. Heydarpour, Y.; Malekzadeh, P.; Dimitri, R.; Tornabene, F. Thermoelastic Analysis of Functionally Graded Cylindrical Panels with Piezoelectric Layers. Appl. Sci. 2020, 10, 1397. [CrossRef]

12. Bagherizadeh, E.; Kiani, Y.; Eslami, M.R. Mechanical buckling of functionally graded material cylindrical shells surrounded by Pasternak elastic foundation. Compos. Struct. 2011, 93, 3063-3071. [CrossRef]

13. Allahkarami, F.; Tohidi, H.; Dimitri, R.; Tornabene, F. Dynamic Stability of Bi-Directional Functionally Graded Porous Cylindrical Shells Embedded in an Elastic Foundation. Appl. Sci. 2020, 10, 1345. [CrossRef]

14. Hakula, H.; Laaksonen, M. Frequency Response Analysis of Perforated Shells with Uncertain Materials and Damage. Appl. Sci. 2019, 9, 5299. [CrossRef]

15. Nam, V.H.; Phuong, N.T.; Minh, K.V.; Hieu, P.T. Nonlinear thermo-mechanical buckling and post-buckling of multilayer FGM cylindrical shell reinforced by spiral stiffeners surrounded by elastic foundation subjected to torsional loads. Eur. J. Mech. A Solid 2018, 72, 393-406. [CrossRef]

16. Nam, V.H.; Phuong, N.T.; Trung, N.T. Nonlinear buckling and postbuckling of sandwich FGM cylindrical shells reinforced by spiral stiffeners under torsion loads in thermal environment. Acta Mech. 2019, 230, 3183-3204. [CrossRef]

17. Nam, V.H.; Phuong, N.T.; Doan, C.V.; Trung, N.T. Nonlinear Thermo-Mechanical Stability Analysis of Eccentrically Spiral Stiffened Sandwich Functionally Graded Cylindrical Shells Subjected to External Pressure. Int. J. Appl. Mech. 2019, 11, 1950045. [CrossRef]

18. Phuong, N.T.; Nam, V.H.; Trung, N.T.; Duc, V.M.; Phong, P.V. Nonlinear Stability of Sandwich Functionally Graded Cylindrical Shells with Stiffeners Under Axial Compression in Thermal Environment. Int. J. Struct. Stab. Dyn. 2019, 19, 1950073. [CrossRef]

19. Nam, V.H.; Trung, N.T.; Hoa, L.K. Buckling and postbuckling of porous cylindrical shells with functionally graded composite coating under torsion in thermal environment. Thin Walled Struct. 2019, 144, 106253. [CrossRef]

20. Miller, B.; Ziemiański, L. Maximization of Eigenfrequency Gaps in a Composite Cylindrical Shell Using Genetic Algorithms and Neural Networks. Appl. Sci. 2019, 9, 2754. [CrossRef]

21. Shen, H.S. Postbuckling of nanotube-reinforced composite cylindrical shells in thermal environments, Part I: Axially-loaded shells. Compos. Struct. 2011, 93, 2096-2108. [CrossRef]

22. Shen, H.S. Postbuckling of nanotube-reinforced composite cylindrical shells in thermal environments, Part II: Pressure-loaded shells. Compos. Struct. 2011, 93, 2496-2503. [CrossRef]

23. Shen, H.S. Postbuckling of nanotube-reinforced composite cylindrical panels resting on elastic foundations subjected to lateral pressure in thermal environments. Eng. Struct. 2016, 122, 174-183. [CrossRef]

24. Shen, H.S.; Xiang, Y. Postbuckling of nanotube-reinforced composite cylindrical shells under combined axial and radial mechanical loads in thermal environment. Compos. Part B Eng. 2013, 52, 311-322. [CrossRef]

25. Jam, J.E.; Kiani, Y. Buckling of pressurized functionally graded carbon nanotube reinforced conical shells. Compos. Struct. 2015, 125, 586-595. [CrossRef]

26. Kiani, Y. Dynamics of FG-CNT reinforced composite cylindrical panel subjected to moving load. Thin Walled Struct. 2017, 111, 48-57. [CrossRef]

27. Kiani, Y. Analysis of FG-CNT reinforced composite conical panel subjected to moving load using Ritz method. Thin Walled Struct. 2017, 119, 47-57. [CrossRef]

28. Kiani, Y.; Dimitri, R.; Tornabene, F. Free vibration of FG-CNT reinforced composite skew cylindrical shells using the Chebyshev-Ritz formulation. Compos. Part B Eng. 2018, 147, 169-177. [CrossRef] 
29. Hajmohammad, M.H.; Kolahchi, R.; Zarei, M.S.; Maleki, M. Earthquake induced dynamic deflection of submerged viscoelastic cylindrical shell reinforced by agglomerated CNTs considering thermal and moisture effects. Compos. Struct. 2018, 187, 498-508. [CrossRef]

30. Hajmohammad, M.H.; Farrokhian, A.; Kolahchi, R. Smart control and vibration of viscoelastic actuator-multiphase nanocomposite conical shells-sensor considering hygrothermal load based on layerwise theory. Aerosp. Sci. Technol. 2018, 78, 260-270. [CrossRef]

31. Hosseini, H.; Kolahchi, R. Seismic response of functionally graded-carbon nanotubes-reinforced submerged viscoelastic cylindrical shell in hygrothermal environment. Physica E Low Dimens. Syst. Nanostruct. 2018, 102, 101-109. [CrossRef]

32. Jiao, P.; Chen, Z.; Li, Y.; Ma, H.; Wu, J. Dynamic buckling analyses of functionally graded carbon nanotubes reinforced composite (FG-CNTRC) cylindrical shell under axial power-law time-varying displacement load. Compos. Struct. 2019, 220, 784-797. [CrossRef]

33. Qin, Z.; Pang, X.; Safaei, B.; Chu, F. Free vibration analysis of rotating functionally graded CNT reinforced composite cylindrical shells with arbitrary boundary conditions. Compos. Struct. 2019, 220, 847-860. [CrossRef]

34. Torabi, J.; Ansari, R.; Hassani, R. Numerical study on the thermal buckling analysis of CNT-reinforced composite plates with different shapes based on the higher-order shear deformation theory. Eur. J. Mech. A Solid 2019, 73, 144-160. [CrossRef]

35. Vinyas, M. A higher-order free vibration analysis of carbon nanotube-reinforced magneto-electro-elastic plates using finite element methods. Compos. Part B Eng. 2019, 158, 286-301. [CrossRef]

36. SafarPour, H.; Ghanbari, B.; Ghadiri, M. Buckling and free vibration analysis of high speed rotating carbon nanotube reinforced cylindrical piezoelectric shell. Appl. Math. Model. 2019, 65, 428-442. [CrossRef]

37. Zhao, J.; Choe, K.; Shuai, C.; Wang, A.; Wang, Q. Free vibration analysis of functionally graded carbon nanotube reinforced composite truncated conical panels with general boundary conditions. Compos. Part $B$ Eng. 2019, 160, 225-240. [CrossRef]

38. Sofiyev, A.H.; Turkaslan, B.E.; Bayramov, R.P.; Sala, M.U. Analytical solution of stability of FG-CNTRC conical shells under external pressures. Thin Walled Struct. 2019, 144, 106338. [CrossRef]

39. Ghasemi, A.R.; Mohandes, M.; Dimitri, R.; Tornabene, F. Agglomeration effects on the vibrations of CNTs/fiber/polymer/metal hybrid laminates cylindrical shell. Compos. Part B Eng. 2019, 167, 700-716. [CrossRef]

40. Arefi, M.; Masoud, M.; Sara, A.A.; Rabczuk, T. FSDT electro-elastic analysis of FG-CNTRC cylindrical three-layered pressure vessels with piezoelectric face-sheets. Thin Walled Struct. 2019, 144, 106320. [CrossRef]

41. Mallek, H.; Jrad, H.; Algahtani, A.; Wali, M.; Dammak, F. Geometrically non-linear analysis of FG-CNTRC shell structures with surface-bonded piezoelectric layers. Comput. Methods Appl. Mech. Eng. 2019, 347, 679-699. [CrossRef]

42. Chakraborty, S.; Dey, T.; Kumar, R. Stability and vibration analysis of CNT-Reinforced functionally graded laminated composite cylindrical shell panels using semi-analytical approach. Compos. Part B Eng. 2019, 168, 1-14. [CrossRef]

43. Dindarloo, H.M.; Li, L. Vibration analysis of carbon nanotubes reinforced isotropic doubly-curved nanoshells using nonlocal elasticity theory based on a new higher order shear deformation theory. Compos. Part B Eng. 2019, 175, 107170. [CrossRef]

44. Khosravi, S.; Arvin, H.; Kiani, Y. Interactive thermal and inertial buckling of rotating temperature-dependent FG-CNT reinforced composite beams. Compos. Part B Eng. 2019, 175, 107178. [CrossRef]

45. Zhou, T.; Song, Y. Three-dimensional nonlinear bending analysis of FG-CNTs reinforced composite plates using the element-free Galerkin method based on the S-R decomposition theorem. Compos. Struct. 2019, 207, 519-530. [CrossRef]

46. Beni, N.N. Free vibration analysis of annular sector sandwich plates with FG-CNT reinforced composite face-sheets based on the Carrera's Unified Formulation. Compos. Struct. 2019, 214, 269-292. [CrossRef]

47. Fang, H.; Tan, P.; Du, X.; Li, B.; Yang, K.; Zhang, Y. Numerical and Experimental Investigation of the Effect of Traffic Load on the Mechanical Characteristics of HDPE Double-Wall Corrugated Pipe. Appl. Sci. 2020, 10, 627. [CrossRef] 
48. Xia, Y.; Friswell, M.I.; Flores, E.I.S. Equivalent models of corrugated panels. Int. J. Solids Struct. 2012, 49, 1453-1462. [CrossRef]

49. Brush, D.D.; Almroth, B.O. Buckling of Bars, Plates and Shells; Mc. Graw-Hill: New York, NY, USA, 1975.

50. Han, Y.; Elliott, J. Molecular dynamics simulations of the elastic properties of polymer/carbon nanotube composites. Comp. Mater. Sci. 2007, 39, 315-323. [CrossRef]

(c)

(C) 2020 by the authors. Licensee MDPI, Basel, Switzerland. This article is an open access article distributed under the terms and conditions of the Creative Commons Attribution (CC BY) license (http://creativecommons.org/licenses/by/4.0/). 